\title{
Adolescents Knowledge Regarding Harmful Effects of Junk food
}

\author{
Ms. Vandana Sharma \\ (Child Health Nursing /BFUHS, India)
}

\begin{abstract}
Like very rose has a thorn, the fast food also called Junk food; on one side they are easy to prepare and cheap and on other side these foods have many harmful effects on health. Improving nutrition knowledge among children may help them to make healthier food choices. A Pre-experimental study was conducted to assess the effectiveness of structured teaching program on knowledge regarding harmful effects of Junk food among adolescents. This study was conducted in 3 selected schools at District Jalandhar, Punjab. Total 60 adolescents those who met the inclusion and exclusion criteria were selected by non probability convenience sampling technique. The pre-test was taken by using self structured questionnaire followed by structured teaching programme. After 7 days post- test was taken. The mean percentage of the knowledge score of post test (22.88) was higher than pre test (12.96). The ' $t$ ' value for total pre test and post test was 16.76.The difference between pre-test knowledge score and post test knowledge scores was 9.92. It means the knowledge score increased after structured teaching programme. The findings of study reveals that the education had a vital role in improving the knowledge of adolescents regarding harmful effects of Junk food.
\end{abstract}

\section{Introduction}

"Don't dig your grave with your own knife and fork." - English Proverb Next to air we breathe and water we drink, food has been basic to our existence. Food is necessary for energy, for growth, repair, and for health. Our health depends on what we eat daily. Now in these days most people like Junk food and it is very popular among adults as well as in children. Socio- economic trends, such as longer work hours, more women employed outside the home and a high number of single-parent households have changed the way families obtain their meals.

The famous microbiologist Dr. Michael F. Jacobson coined the phrase "Junk Food" in 1972 to describe unhealthy or non-nutritious food. There are numerous additives that must be used in Junk food and they can cause health problems. For example Monosodium glutamate (MSG), is a flavor enhancer commonly added to Chinese food, canned vegetables, soups and processed meats that causes hypothyroidism ,headache, nausea, weakness, difficulty in breathing, drowsiness, rapid heartbeat, and chest pain.

Teenagers are frequent visitors to fast food restaurants, different store, visits occur immediately after school. The best way to persuade a child to eat healthy foods is by allowing them to read up on info about Junk food. There is a lot of information on Junk food that children can get through website, schools, children's magazines, and so on. Parents who let their children access such information Junk food are creating awareness and are thereby encouraging their children to move towards healthier eating habits.

\subsection{Need Of Study}

Adolescence is the only time following infancy when the rate of growth actually increases. This sudden growth spurt is associated with hormonal, cognitive, and emotional changes that make adolescence an especially vulnerable period of life nutritionally. If we discuss about eating pattern of adolescents or teenagers than it is concluded that after-school activities and active social lives, busy schedules may lead to meal skipping or eating away from home. Their diet includes burgers, pizza, hotdogs, and cold - drinks. However by eating Junk food, a teenager will not get any nutrients required for proper functioning of the body. Junk food is full of fat and calories; a lot more than what is required for the body on a daily basis. This makes the teenager more prone to heart disease.

Research has shown that Junk food consumption is linked to behavioral disorders. Many people, especially children, suffer from ADHD(Attention deficit hyperactive disorder) due to additives and added sugar in Junk food. Drinking a single $330 \mathrm{ml}$ can a day of sugary drinks translates to more than one pound $(0.45 \mathrm{~kg})$ of weight gain every month. According to NSS (National Sample Survey) data for the category beverages, refreshments and processed foods, the money spent on Junk food in India was almost 25 per cent higher than the Rs 33,000-crore spent on edible oils.

According to NFHS (National Federation of State High School Associations) there is a list India ranked in order of percentage of people who are overweight or obese in which Punjab is in first position. Government surveys have shown that at least $16 \%$ of children and adolescents age 6 to 19 years old are considered overweight and at least $11 \%$ adolescents now are classified as obese. 
From above reports it is necessary for adolescents to know about the harmful effects of Junk food so that they can control the disease conditions and improve their health status. Therefore this study is planned to design structured teaching program to educate the adolescents regarding harmful effects of Junk food which in turn is expected to increase the awareness about harmful effects of Junk food in adolescents and prevent a lot of dangerous disease conditions.

\subsection{Statement of Problem:}

A Pre-experimental study on the effectiveness of structured teaching programme on knowledge regarding harmful effects of Junk food among adolescents in selected schools at District Jalandhar, Punjab, 2012.

\subsection{Objectives:}

- To assess the pre- test knowledge of adolescents regarding harmful effects of Junk food.

- To plan and implement structured teaching program regarding harmful effects of Junk food among adolescents.

- To assess post - test knowledge of adolescents regarding harmful effects of Junk food.

- To compare pre- test and post -test knowledge of adolescents regarding harmful effects of Junk food.

- To determine the association between knowledge regarding harmful effects of Junk food with selected socio- demographic variables.

\subsection{Hypothesis:}

$\mathrm{H}_{1}$ : There will be significant difference between pre test and post test knowledge scores of adolescents on harmful effects of Junk food.

$\mathrm{H}_{0}$ : There will not be significant difference between pre test and post test knowledge scores of adolescents on harmful effects of Junk food.

\subsection{Conceptual Framework:} attainment

The conceptual frame work selected for this study was based on Imogene King's theory of goal

\section{Material and Methods}

The research design used in this study was Pre- experimental in nature. The study was conducted at selected 3 Schools at District Jalandhar, Punjab. The schools were New National Public School, Salempur ; Govt. Middle School, Salempur ; Govt. Sec. School, Tehlan . The sample of 60 adolescents on the basis of inclusion and exclusion criteria were selected. Non probability convenience sampling technique was used for this study. The tool used for the study was the structured knowledge questionnaire consisting of section I (Socio- demographic variables such as Age, Sex, Education standard of adolescent, Residence, Family income and availability of Junk food in school canteen and section II (consisting of 30 items related to Knowledge regarding harmful effects of Junk food). The content validity of structured questionnaire was ensured by submitting the tool to the experts in the field of community health nursing, child health nursing, and nutrition. A pilot study was conducted on 10 adolescents in the selected school (Govt. Senior secondary school, Dhanowali, Jalandhar, Punjab. Reliability of tool was established by Karl Pearson's Correlation coefficient. The reliability of tool was calculated and it was 0.78 .

\subsection{Related to Socio demographic variables of adolescents:}

\section{Results and Findings}

According to sample characteristics of adolescents the majority of adolescents $30(50.00 \%)$ were in age group 15-16 years and males were more in number 31(51.67\%). The maximum adolescents ( $93.33 \%)$ belongs to rural area .According to educational standard of adolescent the maximum adolescents $18(30.00 \%)$ were from class 11th. The majority of adolescents 28 (46.67\%) had family monthly income $<5000$ and availability of Junk food in schools was $100 \%$. 


\subsection{Related to pre-test and post-test knowledge scores of adolescents regarding harmful effects of Junk} food.

Figure 1: Percentage of adolescents in pre test according to level of knowledge

Pre-test knowledge level of adolescents

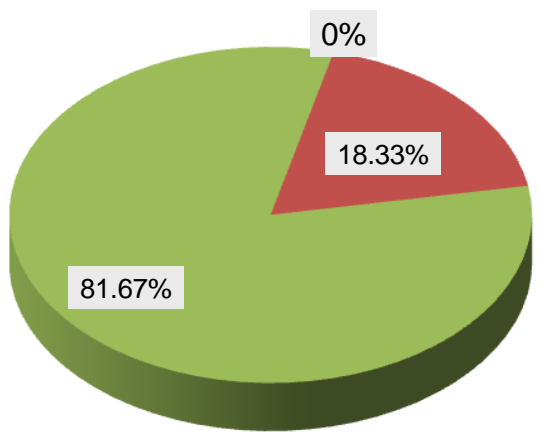

- Good

- Average

Below

Average

Figure

depicts that most of adolescents $81.67 \%$ (49) having below average knowledge regarding harmful effects of Junk food followed by $18.33 \%$ (11) adolescents had average knowledge. In pre - test there was no adolescent had good knowledge about harmful effects of Junk food.

Figure 2 Percentage of adolescents in post test according to level of knowledge

Post-test knowledge level of adolescents

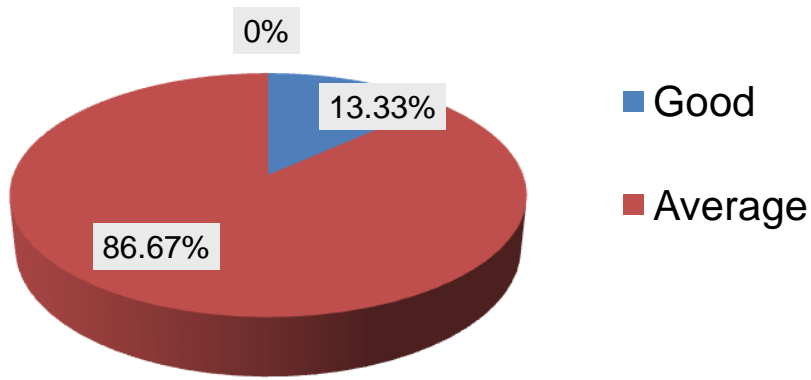

Figure 2 depicts that in post test, the maximum $86.67 \%(52)$ adolescents having average knowledge followed by $13.33 \%$ (08) adolescents having good knowledge regarding harmful effects of Junk food. In post test no adolescents had below average knowledge.

Figure 3 Comparison of pre test- post test mean knowledge scores

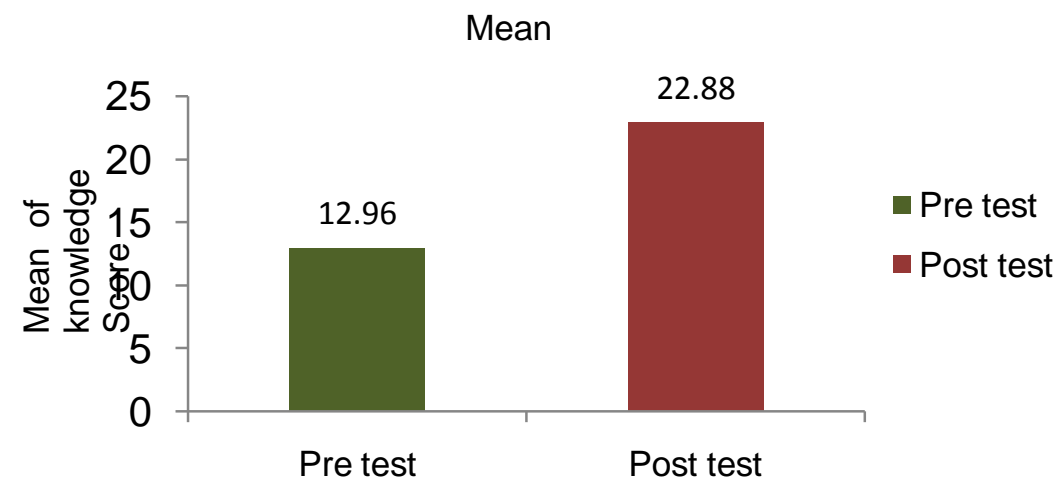


Figure 3 shows that the mean pre-test knowledge score was (12.96)and post - test mean knowledge score was (22.88). The difference between pre- test mean knowledge score and post- test mean knowledge score was 9.92. and ' $t$ ' cal 16.76 is greater than $2.58 \sigma$ at $1 \%$ level of significance which shows high level of significance. It means, structured teaching program helps in providing the knowledge.

\subsection{Related to impact of socio-demographic variables on the knowledge scores}

Among socio- demographic variables only gender had association with knowledge mean scores.

\section{Nursing Implications}

The nursing implications of the study could be discussed under nursing service, nursing education, nursing research and nursing administration.

Nursing Service

- The Expanded role of the professional nurse emphasizes those activities, which promote health and preventive behaviour among consumers. So, by providing education about harmful effects of Junk food to people ,the health diseases can be prevented .

- It helps the nurses to plan health education on diseases related to Junk food.

- On the basis of community research people attitude should be modified about eating habits.

\section{Nursing Education}

- Incorporate nutrition education lessons into the curriculum. Expose students to healthful foods during nutrition education lessons. Junk food consumption tends to the occurrence of many life-threatening diseases during adulthood and later life. Studies proved that school based educational programme might be effective in influencing adolescents to choose a healthier diet. The health teaching programme is an effective teaching strategy, which can be used for this purpose.

\section{Nursing Administration}

- Nurse administrators are the backbone for providing facilities to improve knowledge on nutrition. Administrative policies should be formulated at the large scale to lessen the consumption of Junk food.

\section{Nursing Research}

- Finding of study will act as catalyst to carry out more research on large population or sample from different areas of community.

\section{Conclusion}

In this study pre test knowledge mean scores of adolescents regarding harmful effects of Junk food were less than post test knowledge mean scores. Structured teaching program helped to gain knowledge. All moved up that is from 0-15 to higher scores towards average and good scores. The study findings implied that the education has a vital role in improving the knowledge of adolescents regarding harmful effects of Junk food. So, it was concluded that by providing teaching program on harmful effects of Junk food, the knowledge of adolescents improved.

\section{Reference}

[1]. Sohi Darshan. Nutrition and dietetics. $1^{\text {st }}$ ed. Medical publishers; 2010.p.3-4

[2]. Health and study .Diet . February 1,2012. Available from URL: http://library.thinkquest.org/C0124861/health/diet/diet_intro.html

[3]. What is a Junk Food? Junk Food Pictures.February 1,2012 .Available from URL http://www.fatfreekitchen.com/Junkfoods/Junkfoods1.html

[4]. Debby Demory -Luce,LD Craiq Jensen. Fast food for children and adolescents. February 1,2012 .Available from URL http://www.uptodate.com/contents/fast-food-for-children-and-adolescents

[5]. Syed Rehan. Ezine articles. Junk food impact on health. March7, 2011. Available from URL:file:///D:/Junk\%20Food\%20Impact\%20on\%20Health.htm

[6]. Wikipedia-The free encyclopedia. Junk food. March 1, 2011. Available from URL: http://en.wikipedia.org/wiki/Junk_food 